This is a post print version of an article published by SAGE in Qualitative Social Work in 3(3) 2004, pp. 259-275. Available online: DOI:10.1177/1473325004045665.

\title{
TALKING BACK TO STIGMATIZED IDENTITIES
}

\section{Negotiation of culturally dominant categorizations in interviews with shelter residents}

Kirsi Juhila

\section{Abstract}

The article is based on interviews with 17 shelter residents. The shelters, meant for homeless people, can be regarded as institutions of last-resort help of the Finnish welfare state. The culturally dominant way of categorizing both shelters and their residents is negative, producing stigmatized identities. The questions asked in this study are (1) do the shelter residents make references to the stigmatized identities produced by the culturally dominant categorizations of the shelters and their residents and, if and when they do so, (2) how do they talk back to these identities, i.e., how do they construct their own identities in relation to the dominant ones? The interviewees often refer to their 'given' identities, but instead of taking them for granted in any way, adopt a critical position towards them. The talking back consists in a subtle negotiation in which one's own identity is compared with the identities of either the shelter or the co-residents. The interviewees stress, on the one hand, the ordinary quality of the shelter and its residents or, on the other, their own ordinariness. This rhetoric of the ordinary is used to resist the definition, which states that the characteristics and behaviour of shelter residents make them a negative exception to the mainstream population. On the other hand, it is also possible to locate in the residents' talking back an identity politics, which attempts to 
replace the dominant categorizations with completely different ways of representing the shelter and its residents, ways which are conscious of diversity.

Keywords: culturally dominant categorization, talking back, stigmatized identity, category, rhetoric of the ordinary, identity politics

\section{Introduction}

The context of this study is formed by two services in the Finnish welfare state: a shelter intended for homeless men and a shelter intended for homeless women. The shelters are meant to people with no fixed housing or who for one reason or another are unable to live at home. These services can be regarded as institutions in the sense that people do not just visit them but live their everyday lives in them. Living is rather regulated because the shelters have settled daily routines and rules about staying there. The personnel consist of the shelter manager, a social worker, counsellors, supervisors and nurses.

The societal status of the shelters is low. They are not universal services of the welfare state targeted for all citizens but residual or last-resort places. The shelters are meant for people who do not have any other coping resources available, not any of their own, nor any provided by the welfare state. In the official reports of the shelters the residents are described as having multiple problems. In addition to homelessness, many are classified as having both substance abuse and mental health problems. In the very same reports the residents are also described as socially excluded persons or being at risk of becoming such. The public image of the shelters very much resembles these descriptions. They are seen as places where people are forced to go in nonalternative situations. The residents of the shelters are often characterised with a moralistic tone. 
They are seen as unable to take responsibility for their own lives, as persons who perhaps do not deserve the help of society at all. The discussion about undeserving citizens is connected to neoliberalistic thinking, which has gained strength in European countries and also in Finland during the last ten years. Neo-liberalism appreciates responsible citizens and claims that a welfare state can create an unhealthy dependency culture among some groups of citizens (Julkunen, 2002; Jordan \& Jordan, 2000).

In the above, I have described the shelters and their residents as they appear when seen from the perspective of the official politics of the shelters and the public opinion; the shelters are last-resort welfare institutions providing modest accommodation and services for people excluded from the mainstream life and who perhaps do not take enough responsibility for their own lives. In this article I define these definitions as culturally dominant categorizations that produce stigmatized identities both to the shelters and to their residents. These categorizations serve as a contextual frame in my analysis.

In the following I will turn the perspective around, that is, allow the shelter residents to have their say. The main focus of this article is on analysing how they characterise the shelter and themselves as residents, in other words, what identities they construct, firstly for the place and secondly for its residents, including themselves. We will notice that the culturally dominant categorizations, which are clearly stigmatizing from the residents' points of views, also exist in their talk. The fact that they make references them prove for its part that these categorizations have a strong position in the Finnish cultural reality. However, the residents do not necessarily take dominant categorizations for granted. On the contrary, there are elements of talking back to them in the residents' talk. 
According to Jan Fook (2002: 72-4) the identities of service users based on fixed social structures can be stigmatizing since they do not allow for variety and change and since they come from the direction of dominant discourses. Therefore they can have a disempowering effect. What I intend to do in this article is to shake the culturally dominant categorizations of the shelters and their residents by listening to the talking back stories of the parties concerned. As Nigel Parton and Patrick O'Byrne (2000: 184) put it: "Such stories should not be diminished by the imposition of categories imported from an external, perhaps professional or organisational, world."

\section{Aim of the study and empirical material}

The aim of the article is to seek answers to the following two questions. (1) Do the shelter residents make references to the stigmatized identities produced by the culturally dominant categorizations of the shelters and their residents and, if and when they do so, (2) how do they talk back to these identities, i.e., how do they construct their own identities in relation to the dominant ones? My empirical material consists of 17 interviews with shelter residents (9 women, 8 men). The interviews are free form and make use of the ideas of active interviews (Holstein \& Gubrium, 1995) and narrative interviews (Riessman, 2001). Before moving on to the analysis of the interviews I will firstly present my basic concepts - categories and stigmatized identities - and my approach to identity research, which is based on the idea of stigmatizing categorization. Secondly, I will introduce my third concept - talking back - and show why interviews provide appropriate material for a study of talking back to stigmatized identities. 


\section{Categories and stigmatized identities}

Putting people and things into groups, or categorization, is an inherent part of the interaction between individuals (Bowker \& Star, 2000: 1-32; Douglas, 1966). It occurs everywhere, for without it we would be unable to orientate to one another in different situations and to co-ordinate joint action. In other words, categorization maintains and produces social and moral order. Harvey Sacks was the researcher, who became interested in categories which are present in action but often remain unnoticed. In his research, he began to make categories visible by showing how significantly they organise our joint action. Sacks (1992: 40) writes that "a great deal of knowledge that members of a society have about the society is stored in terms of the categories". Thus, categories are shared and public cultural resources through which we construct our understanding of society, ourselves and others. Particular categories are tied to certain presumed characteristics or activities.

Although categories created in and through interaction have a social and cultural history, this does not mean that the past would rigidly dictate how people interact with each other 'here and now'. Developing Sacks's ideas further, Stephen Hester and Peter Eglin (1997) stress, that society and culture must be studied as action, in which categorization holds a central role. People evoke categories which enable them to act in given situations. This is why categories should be studied as an activity carried out in particular local contexts, in my case in the interviews with the shelter residents.

Very often categorization is about defining people. We continuously place ourselves and others into categories, with which we link certain characteristics, features and activities. Placing people in a category is inevitably consequential, not least because categories produce social identities for people. In the words of Charles Antaki and Sue Widdicombe (1998: 3), "for a person to "have an 
identity' - whether he or she is the person speaking, being spoken to, or being spoken about - is to cast into a category with associated characteristics or features". Categories are knowledge which is so deeply shared culturally and taken for granted that often the simple mention of a category is enough for us to have expectations of what the persons belonging to it are like and how they should behave. For instance, we 'know' what kind of people shelter residents are.

The categorization of people always has two aspects. On the one hand, it preserves harmony in society and facilitates orientation to and encounters with people in different situations. On the other hand, categorization can just as easily maintain discrimination in producing 'identity prisons' charged with negative characteristics for some people (Silverman, 1998, 88). The latter aspect of categorization is the focus of this article. A culturally dominant categorization, which is mainly linked to negative characterisations, can be defined as a stigmatized identity (Goffman, 1961 and 1963). And as I wrote in the introduction, my claim is that Finnish shelter residents are carrying this kind of stigmatized identity.

Erving Goffman (1961) studied the moral careers and identities of people living in total institutions, such as prisons or mental hospitals, in a way which can also be usefully applied when studying shelters. Life in these institutions and their residents are culturally mainly linked with negative characteristics; people who have landed up there are thought to have failed in their lives in one way or another. Those assigned to these stigmatizing categories cannot ignore them. When people refer to themselves in different contexts, they tend to comply with the expectations of other people, in other words, they use identities which the others can recognise (Gubrium \& Holstein, 2001: 7). Matters become more complicated if co-actors expect and offer a stigmatized position to a person. The bearers of a stigmatized identity recognise the definitions, which are directed to them, but it is 
understandably difficult to accept such a position (cf. Morgan, 2000: 194). They may adopt a polemical relationship with the stigmatized identity, i.e., talk back to it in one way or another.

\section{Talking back to stigmatized identities in interviews}

Stuart Hall (1988) writes that identity consists of an invention formed at the unstable meeting point of countless stories of subjectivity and the stories of history and culture. Identities become real and are learned at a certain moment in history on the level of meanings. Since identities are 'inventions' in this sense and are dialogically constructed, their meanings cannot be permanently fixed. It is possible to assume culturally strong identities and negotiate new meanings. It is this negotiability which enables the activity which I call talking back to stigmatized identities.

Talking back is always a dialogue with culturally dominant categorizations. It would not exist without dominant meanings. With this as my starting-point, I define talking back as consisting of acts which comment on and resist stigmatized identities related to culturally dominant categorizations and which have the function of presenting the difference between one's own self or a group and the dominant definition. Talking back is not characterised so much by a downright denial of the stigmatized identity as by a subtle negotiation which calls into question dominant categorizations and evokes the possibilities of alternative identities. This negotiation is what I attempt to identify in the interviews with the shelter residents.

Carolyn Baker (1997) has studied the negotiation of identity categories in interviews. She treats both interviewers and interviewees as competent members of the culture who have analytic resources that they use in interview talk. Thus, the participants work with their own and the other's categories relevant to the interview encounter. Baker (1997: 137) shows, for instance, how the 
people positioned as 'adolescents' in the interview produced answers "which displayed their cultural knowledge about adult constructions of adolescence". A similar process can be located in the interviews with the shelter residents. This is why interviews are excellent research material for the study of talking back to stigmatized identities. The interview context actually invites such talk, because people are selected for interviews as representatives of the category of 'shelter residents'. The people are interviewed as the residents of a certain shelter, the interviewers have expressed an interest in how they ended up there, how they look upon their life there and how they see their future from their present position. Thus, negotiation on categories of identity comes up repeatedly in the interviews. Both the interviewer and the interviewee are orientated towards certain categories. On the one hand, the interviewer tacitly asks the interviewee to confirm a certain category affiliation and, on the other hand, the interviewee accepts the categorization offered or talks back to a way of being seen (Widdicombe \& Wooffitt, 1995: 102-4).

I will now move on to present the talk of the shelter residents. According to the two questions asked at the outset, I will concentrate on instances in the interviews where the residents both refer and talk back to stigmatized identities. My focus will be strictly on interview talk because in category analysis the interest is on how people evoke and use cultural categories and identities in particular local situations (Hester \& Eglin, 1997). For that reason I will not explain the talk of interviewees for instance by describing how long they have been living in the shelter or what kind of other clienthoods they have previously had. These issues are meaningful only if the interviewees themselves produce them as such.

Instances of talking back are in no way exceptional in the interviews. On the contrary, I identified such instances in all the interviews except one. Talking back is not, however, a main tone in the interviews. The instances are rather short and they are embedded in several discussion themes. 
Talking back appears without any obvious question or comment made by the interviewer; issues around stigma were not among the themes planned in advance for the interviews. Because talking back is about subtle negotiation of identities, the instances in the interviews are not in a form of straightforward resistance, such as 'I don't approve of the way I'm being labelled as a shelter resident'. Instead, talking back occurs as indirect and delicate references to culturally dominant categorizations. To make this indirectness and delicacy visible it is necessary to present the data as naturally as possible and also analyse it in detail. This method does not allow me to use very many extracts in the article. I have chosen four instances of talking back that are among the strongest ones in the whole data corpus. The chosen extracts also represent two aspects which recur in the interview talk. These aspects are (1) comparing one's own identity to the shelter's identity and (2) comparing one's own identity to the co-residents' identities.

The chosen four extracts may be placed along a chronological continuum. The first extract deals with life before the shelter, the two middle ones talk about present life in the shelter, and the final one constructs a vision of the future. The two first extracts are derived from interviews at the women's shelter, the two last ones from the interviews at the men's shelter.

\section{Comparing one's own identity to the shelter's identity}

When listening to the interviewees' talk they seem to be well aware of the culturally dominant categorizations which define the shelters as last-resort welfare institutions providing modest accommodation and services for people excluded from the mainstream life and who perhaps do not take enough responsibility for their own lives. The problems associated with the stigma assigned to the shelter are to be heard from the subtle ways in which they speak of the personal significance of the shelter and of the fact that they live there. A common way of dealing with this identity problem 
is to compare one's own identity with the shelter's identity. The first extract deals with this. The female interviewee (W) has ended up as a homeless person in the shelter after having separated from her partner. This is her first time in the shelter.

\section{Extract 1}

I: $\quad$ Well what was your situation when you came here?

W: $\quad$ Well of course it was really difficult.

I: $\quad$ Right

W: $\quad$ Because when I was here before to see this place, I couldn't even imagine.

I: $\quad$ Right

W: $\quad$ That's I got all at once a sort of panic, you know, I must get out this place right away, I'd never come here.

I: $\quad$ Right, what was it exactly at that time, I mean what was it that caused the panic or what were the things which felt like that you wouldn't?

W: Well, I don't know, I suppose I thought that this being this being after all a kind of institution in its way.

This extract shows how the context of the interview evokes certain culturally dominant categorizations. The interviewer poses a seemingly innocent question about the interviewee's situation on entering the shelter, and the interviewee's answer hints at culturally shared knowledge. For example, she does not start by listing the concrete details of the situation, but describes her experience ("well of course it was really difficult"). The description of the experience presupposes the knowledge in the other that you do not enter a place like this with a happy heart. In other words, the reasons why it was "really difficult" need not be explained, since both participants are already familiar with this. My interpretation is that "really difficult" is a description, which the interviewee links with the institution and its stigmatized identity. 
The manner of the story contributes to the stigma linked to the institution. By this I mean that the interviewee describes how she approached the shelter in two stages and at the same time from two different viewpoints. The first one is located further back in time, the viewpoint of someone who "was here before to see this place". This viewpoint refers to the interviewee's past identity, to the person who is looking at the shelter and the life in there as an outsider. This person cannot even imagine entering a shelter, the mere thought causes panic. As an explanation to the interviewer's follow-up question on the impossibility of entering a shelter, the interviewee says "this being after all a kind of institution in its way". The concept of institution, again, is produced by the interviewee as a thing shared. A reference to an institution is sufficient to explain the "evil" linked with the place. In addition to the identity of the person who "was here before to see this place", the interviewee also constructs another identity for herself, which is more recent than the first one, but still situated in the past. This is the identity of the newcomer, a person about to enter the shelter and forced to re-create her relationship to the shelter. There is a significant conflict between these identities. The former could never have imagined entering this place, while the latter is nevertheless doing it.

The manner in which the interviewee uses the two identities mentioned above constitutes stigma management, which resists a given "identity prison" charged with negative characteristics, while at the same time recognising the existence of the stigmatized identity. The plot of the story is as follows: in the eyes of outsiders, which is what the interviewee used to be, the shelter and thus the people living there appear negative, which is why a person entering the shelter must examine himor herself against this culturally dominant categorization. The interviewee thus creates a narrative that she has grappled with the stigmatized vision of herself and has ultimately defined her own identity. The talking back to stigmatized identities culminates at a later stage during the interview, as the interviewee describes how she has resolved the conflict. By now she no longer feels that she 
carries a stigma, and also sees her co-residents as diverse people, similar to anybody else encountered in the street: "when walking in the streets you couldn't know at all who's from where...because there are so many kinds of us there". Thus, as a group, they are not distinguished by a set cluster of characteristics, by a stigma.

Similar talking back is present in the second extract, in which the interviewee (W) describes the shelter from the inside, from the angle of living there at the moment. Her reason for living in the shelter is domestic violence that has forced her to seek refuge. She has been living in the shelter also once before because of the same reason.

\section{Extract 2}

W: I never considered that this was a shelter for alcoholics, although

I'm sure there are women here who abuse alcohol,

I repeat that this is a very clean place.

I: $\quad$ Right

W: $\quad$ And here are people from different social classes.

In another place, I name no names but some place

for alcoholics where you could only have down-and-outs

or people who live on welfare

As in the first extract, here, too, the interviewee's talk allows the interpretation that she assumes the listener to be familiar with the shelter's stigmatized identity. One of the culturally dominant ways of categorizing a shelter is to consider it 'a shelter for alcoholics'. The interviewee places her words against this categorization by appealing to her experience as someone who knows, who sees things from the inside. The talking back is very definite. She has "never considered" the shelter to be what outsiders usually classify it as. The cultural weight of the negative categorization attached to the shelter is, however, shown by the fact that the interviewee thinks it necessary to comment on it. She 
is not free to describe the shelter according to her own experience until she has deconstructed the negative stigma attached to it. It is only in this way that the truth based on the interviewee's own experiences can be brought out.

The category "shelter for alcoholics" contains the definition of both the shelter and its residents: the shelter is inhabited by alcoholics. In evoking this category and no other the interviewee places herself in opposition with the dominant cultural image, which uniformly categorizes all shelter residents as a certain type, i.e., alcoholics. She states that there are also "women who abuse alcohol" in the shelter, but they are just one group, for the shelter residents come from "different social classes". The reference to different social classes deconstructs not only the assumption that all residents are alcoholics, but also the assumption that they are inevitably all indigent. Adding variety to the image of shelter residents is an act of talking back which also gives space for the construction of the interviewee's own identity, even though she does not speak directly of herself in the extract. She does not have to assume the identity of an indigent alcoholic, because the shelter residents do not belong to this category only.

The stigmatizing categorization of the shelter is also deconstructed by the interviewee through a comparison with another shelter. This other, unnamed place, possibly only contains "down-and-outs or people who live on welfare". Compared with this other place, the shelter inhabited by the interviewee is different. This paradox reveals the weight and sharedness of the culturally dominant categorizations and the difficulty of an individual speaker to disengage from them completely. The interviewee's talking back deconstructs the stigma associated with her own shelter, but at the same time it reproduces the stigma of the other shelter. 
To sum up the first two extracts, in both of them the interviewees argue strongly for the view that the shelter is different from what people commonly think and claim it to be. This is talking back which deconstructs the stigmatized identities of both the shelter and the women staying there. Through this talking back the interviewees open up space for the view that categorizing someone as a shelter resident does not necessarily reveal their characteristics as a certain type. There are many kinds of women in the shelter. The interviewees themselves are a part of this heterogeneous group of women, whose personal identities may be widely heterogeneous in spite of being shelter residents.

\section{Comparing one's own identity to the identities of other shelter residents}

As noted, in the first two examples the interviewees talked back to the culturally dominant stigmatized identities which people have of the institution and thus of its residents. In the following extracts the emphasis is different. In them, men living in shelters compare their own identities to the identities of other shelter residents. The mirror of one's own identity is thus formed by the coresidents instead of the shelter.

The interviewee (M) who speaks in the following extract has been living with his mother on a temporary basis before coming to the shelter. This is not his first period of homelessness and he has also earlier been living in a shelter, although a different one.

\section{Extract 3}

M: $\quad$ So the only thing which makes me different here is, that at least not yet I don't feel like I am an alcoholic and I never have had problems with alcohol or other substances or have been dependent on them. 
I: $\quad$ What sort of people are they who live here?

M: I think those who live here at the moment, some are alcoholics who have a problem with alcohol. Others are here for some other reasons, that's people excluded from society. So it sounds quite ridiculous at this moment to talk about the Scandinavian over-protective society. And Nalle Walhroos [a well-known Finnish business man - KJ] who used to be a Communist would like to see even the last safety nets dismantled. These guys are not necess-, none of them is a bad person.

In this example the interviewee separates himself to some extent from his co-residents. On the one hand, he defines himself as part of the group in saying that he is different in one respect only. On the other hand, this is a significant difference, for alcoholism may well be the strongest feature linked to the culturally dominant category of a shelter resident in Finland. Thus, if this feature does not apply to the interviewee, he is clearly an exception. In this sense we are dealing with resistance towards a certain stigmatized identity imposed on him because he lives in a shelter.

In her following turn, the interviewer takes up the manner in which the interviewee categorizes not only himself, but also his co-residents. The follow-up question is, "What sort of people are they who live here?" In his reply, the interviewee positions himself on the outside and describes the residents and their characteristics from the point of view of a person who does not have an identity of a shelter resident. He does not speak of us, but of those who live here, on whom he has an opinion. The main characteristic of the residents as defined by the interviewee is social exclusion, which may be due to other causes besides alcoholism. The concise characterisation in the answer and the mention of the concept of exclusion could easily have been found in an administrative report or in a research report, for that matter. 
Overall, it can be argued that the interviewee sees himself as one of the ordinary people and thus as someone capable of defining shelter residents, others. Thus, the talking back consists in constructing one's own identity as different and separating oneself from the stigmatized identity culturally linked with shelter residents. However, it is possible to identify other types of talking back elements in the interviewee's talk as well. The interviewee states "so it sounds quite ridiculous at this moment to talk about the Scandinavian over-protective society". By saying that he is distancing himself from the neo-liberalistic opinions, heard in Finland nowadays, which voice the suspicion that certain citizens receive abundant support from the welfare society without having truly merited it. Especially the category of what are called "alcoholic and excluded" persons has been brought up in this context. In his last turn the interviewee also resists the stigmatized definition of the members of this group when he goes on to say: " These guys are not necess-, none of them is a bad person". Thus, though the interviewee separates himself from the group of shelter residents he simultaneously argues for them by resisting certain culturally powerful discriminating and stigmatizing attitudes towards them.

In the last extract, in which the interviewee is looking to the future, the distinction between one's own identity and that of the co-residents is clearer than in Extract 3. The interviewee (M) has a long history of homelessness and bad housing. Before coming to the shelter he had stayed some nights in a friend's flat and some nights on the street.

\section{Extract 4}

M: She said, I mean this young social- [refers to the social worker - KJ] that

I: $\quad$ Right

M: this isn't like your place, you don't have the kind of problem or

I: $\quad$ Do you agree that this isn't your place?

M Well of course, I agree that there's no way 
I could get used to going on like this for the rest of my life.

I want to move on with my life

In this example, as in all the previous ones, the shelter's stigmatized identity is assumed to be obvious. It is a place meant for people who have a certain problem. If the problem does not exist, then the person is in the wrong place. Those having the problem, those who fit in the shelter, are the ones with a stigmatized identity. The interviewee talks back to this stigmatized identity as far as he himself is concerned. The talking back makes use of the expert opinion of a social worker who has said that the interviewee does not have the kind of problem which would force him to remain in the shelter. The interviewer poses an 'unnecessary' question as to whether the interviewee agrees with the expert's opinion. The question is unnecessary, because the matter is self-evident to the interviewee, he does not belong in this place.

The self-evident answer contains plenty of information on how the interviewee looks upon both the shelter and its residents. The identities of the shelter and its residents are almost identical. The characteristics of the category of a shelter resident include not only a certain problem, but also adjustment to shelter practices and stagnation, perhaps even giving up. The interviewee does not recognise any of these characteristics in himself (Howe, 2000). His personal identity is constructed as a reverse of these characteristics. He has not got the problem, he does not adjust to the routines in the shelter and he "wants to move on with his life". In a way, he is already looking at his coresidents from the perspective of his future identity as a non shelter resident. The time spent in the shelter has not changed his views on the shelter and its residents, in contrast to what was said by the interviewee in the first extract.

What is common to the two preceding examples is that the interviewees reproduce the shelter as a given context. It is categorized in the men's talk as a place with a strong cultural stigma and a 
certain type of resident. Neither of them attempts to deconstruct and resist this stigma as such. Instead, the talking back consists in insisting that, even if I live here, I am different from the other residents and in this sense actually in the wrong place. In other words, the men do not identify themselves as belonging to the group of shelter residents, and for this reason they do not accept a resident's identity for themselves. The only possibility of completely distancing themselves from this undesirable identity is to try and get away from the shelter. Otherwise, especially if the stay in the shelter is prolonged, the stigmatized identity cannot be avoided.

\section{Conclusions: the rhetoric of the ordinary and identity politics}

The analysis of the interviews with the shelter residents shows that, even though the interviewees make reference to the culturally dominant categorizations related to the shelters, they do not by any means take these for granted. Instead, they may adopt a reflexive or even critical position in relation to them, in other words, talk back to the stigmatized identities. The comparison is made either in relation to the shelter's identity or to the co-residents' identities.

When looking at the whole interview data, comparisons to the shelter's identity are more frequent in the interviews with women, while comparisons to the co-residents' identities are more common in the men's talk. The female interviewees speak very positively about the shelter and stress its importance in their current life situations. Looking from the outside the shelter might carry a stigma, but the insiders see it in a totally different way. Becoming an insider, seeing the good sides of the shelter, is a process that gives argumentative devices to the women to talk back to the culturally dominant categorizations related to the shelter. Unlike the women the male interviewees seem to lack these devices. In their talk the shelter is defined as more or less the same kind of stigmatized place as it is when seen from the outside; it is a place for socially excluded alcoholics. 
What the men talk back is the idea that every shelter resident, including the speaker himself, carries stigmatized characteristics of a shelter resident.

Nevertheless it is not possible to conclude that these different ways of talking back are specific to men or women as such. Rather, the interpretation based on my own cultural knowledge of the local service system is that the difference is due to the different public images of the women's shelter and the men's shelter. Although both shelters are residential services, the men's shelter clearly has a lower status than the women's shelter. Thus, the cultural stigma attached to it is also stronger. This local difference can also be read from the reference made by one of the women interviewees (Extract 2) to a men's shelter, "naming no names", which she considers to be a much worse place than the women's shelter. Since the stigma of the men's shelter is so strong and therefore more difficult to break, talking back is easier if it deals with the distancing of one's personal identity both from the shelter and its residents. In contrast, women have more space for defining both the shelter and its residents as different from culturally dominant categorizations.

On the basis of my analysis it is possible to construct two strategies of talking back, or two ways of deconstructing the stigmatized identity, using either the rhetoric of the ordinary or identity politics. The difference between the strategies is analytical in that they may be used by one and the same interviewee, and sometimes almost simultaneously.

The interviewees' talking back often consists of emphasising the ordinary quality of either the shelter residents or themselves. This rhetoric of the ordinary may be characterised as the activity, which Harvey Sacks (1963) describes with the words "doing being ordinary". An emphasis on the ordinary argues against the stigmatizing definition, which states that shelter residents are a negative exception to the mainstream population as to their characteristics and behaviour. This type of 
talking back is present, for instance, in Extract 2, in which the interviewee stresses that people from several different social classes live in the shelter. The range of people in the shelter is identical to society at large, they are not a group which only consists of the lower class. Shelter residents are ordinary Finns. Stressing one's personal ordinariness, again, is visible in Extracts 3 and 4, in which the interviewees define themselves as different in relation to their co-residents. These are attempts to show that whatever may be said about any member of the population living in shelters is not to be said about me (Sacks, 1992: 44). Thus, the interviewees define themselves as belonging more to the ordinary mainstream population than to the group of shelter residents.

The rhetoric of the ordinary is, on the one hand, very significant for face saving (Goffman, 1955). In situations where others see a person through a stigmatized identity it is very important to present one's self as ordinary and thus distance oneself from the stigma. On the other hand, the rhetoric of the ordinary is a never-ending process and fruitless activity. Culturally dominant categorizations, in my case the stigmatizing characteristics linked to shelters and their residents, are so powerful that they cannot be disproved simply by introducing one contrary case (Silverman, 1998: 75; Sacks, 1992: 336). Thus, stigmatizing categorization is maintained even if people provide examples of exceptionally ordinary shelters or exceptionally ordinary residents, in comparison to culturally dominant categorizations.

I name the second talking-back strategy used by the shelter residents as identity politics. This deals with a struggle over categories, in which another way of presenting the self is sought, in comparison to the discourse coming from the direction of the dominant categorizations. Identity politics is not based on fixed categories, but on the positive meanings of difference. As an example, in Extract 1 the interviewee argues in this direction. Before coming to the shelter she had attached a stigma to the shelter and its residents, but had later changed her views. The change was not due to the 
realisation that shelter residents are ordinary people just like anyone else, but to the realisation that shelters contain the same diversity of people who walk in the streets in the outside world. Instead of one category for 'ordinary people', the interviewee opens up space for variety, for non-stigmatizing differences. Similarly, the interviewee in Extract 4 suggests at positive differences in saying that his co-residents are not bad people even if they may be socially excluded and alcoholic. A person's identity is not only one and of one kind, either ordinary or out of the ordinary, but it is many and of many kinds. All in all identity politics can be seen to be present in the whole data in the sense that both the female and the male interviewees talk in a sympathetic and broadminded way about their fellow residents. They stress the diversity among the residents, but do not pass moral judgement on others. This solidarity is also true in those cases where the interviewee stresses that $\mathrm{s} / \mathrm{he}$ her/himself should not belong to the category of shelter residents (cf. Howe 2000).

In this article I have examined how the shelter residents talk back to the stigmatized identities by which they are defined. I began by describing culturally dominant categorizations related to shelters and their residents. Shelters are residual welfare services whose users are often morally judged. It can be even questioned whether the residents deserve this modest service. In these neo-liberalistic times it is extremely important to listen to the resisting voices of shelter residents or other stigmatized welfare users.

I have analysed talking back accounts by individual people produced in this case in interview situations. Peter Leonard (1997: 170) writes that individual resistance is "insufficient to ensure, to the maximum, the subject's right to agency and the respect of difference". According to him, what is needed in addition to individual actions is collective resistance to the power of dominant cultural discourses. A similar line is adopted by Jan Fook (2002: 84-85; see also Healy, 2000), who says that identity politics can deconstruct stigmatized identities, create space for different identity stories 
and at best could function as a means of empowerment for marginalised groups. Therefore, I conclude with the question as to whether the turning of individual resistance into a collective one is something that could be seen as the task of social work and as its great challenge.

\section{References}

Antaki, Charles and Widdicombe, Sue (1998) 'Identity as an Achievement and as a Tool', in Charles Antaki and Sue Widdicombe (eds) Identities in Talk, pp. 1-14. London: Sage Publications.

Baker, Carolyn (1997) 'Membership Categorization and Interview Accounts', in David Silverman (ed) Qualitative Research: Theory, Method and Practice, pp. 130-143. London: Sage Publications.

Bowker, Geoffrey C. \& Star, Susan Leigh (2000) Sorting Things Out: Classification and Its Consequences. Cambridge: The MIT Press.

Douglas, Mary (1966, reprinted in 1996) Purity and Danger: An Analysis of the Concepts of Pollution and Taboo. London \& New York: Routledge.

Fook, Jan (2002) Social Work: Critical Theory and Practice. London: Sage Publications.

Goffman, Erving (1961, reprinted in 1991) Asylums: Essays on the Social Situation of Mental Patients and Other Inmates. London: Penguin Books.

Goffman, Erving (1964, reprinted in 1990) Stigma: Notes on the Management of Spoiled Identity. London: Penguin Books.

Goffman, Erving (1955) 'On Face Work', Psychiatry 18: 213-231.

Gubrium, Jaber F. and Holstein James A (2001) 'Introduction: Trying Times, Troubled Selves', in Jaber F. Gubrium and James A. Holstein (eds) Institutional Selves: Troubled Identities in a Postmodern World, pp. 1-20. New York \& Oxford: Oxford University Press.

Hall, Stuart (1988) 'Minimal Selves', in Identity, ICA Document nr. 6: 44-46.

Hall, Stuart (1997) 'The Spectacle of the 'Other', in Stuart Hall (ed) Representation: Cultural Representations and Signifying Practices, pp. 223-279. London: Sage Publications \& Open University.

Healy, Karen (2000) Social Work Practices: Contemporary Perspectives on Change. London: Sage Publications. 
Hester, Stephen \& Eglin, Peter (1997) 'The Reflexive Constitution of Category, Predicate and Context in two Settings', in Stephen Hester \& Peter Eglin (eds) Culture in Action: Studies in Membership Categorization Analysis. Studies in Ethnomethodology and Conversation Analysis, No. 4. Washington, D. C.: International Institute for Ethnomethodology and Conversation Analysis \& University Press of America.

Holstein, James A. and Gubrium, Jaber F. (1995) The Active Interview. Thousand Oaks: Sage Publications.

Howe, Leo (2000) 'Scrounger, Worker, Beggarman, Cheat: The Dynamics of Unemployment and the Politics of Resistance in Belfast', Journal of the Royal Anthropological Institute. 4: 531550

Jordan, Bill with Jordan, Charlie (2000) Social Work and the Third Way: Though Love as Social Policy. London: Sage Publications.

Julkunen, Raija (2001) Suunnanmuutos: 1990-luvun sosiaalipoliittinen reformi Suomessa. Tampere: Vastapaino.

Leonard, Peter (1997) Postmodern Welfare: Reconstructing an Emancipatory Project. London: Sage Publications.

Morgan, Steve (2000) 'Three Prisoners' Stories: Talking Back Through Autobiography', In Janet Batsleer and Beth Humphries (eds) Welfare, Exclusion and Political Agency, pp.190-212. London: Routledge.

Parton, Nigel and O’Byrne, Patrick (2000) Constructive Social Work: Towards a New Practice. London: Macmillan.

Riessman, Katherine Kohler (2001) 'Personal Troubles as Social Issues: A Narrative of Infertility in Context', in Ian Shaw and Nick Gould (eds) Qualitative Research in Social Work, pp. 73-82. London: Sage Publications.

Sacks, Harvey (1963, reprinted in 1984) 'On Doing 'Being Ordinary', in J. Maxwell Atkinson and John Heritage (eds) Structures of Social Action: Studies in Conversation Analysis, pp. 413429. London: Macmillan.

Sacks, Harvey (1992) Lectures on Conversation, edited by Gail Jefferson, volume 1. Oxford: Blackwell.

Silverman, David (1998) Harvey Sacks: Social Science and Conversation Analysis. New York: Oxford University Press.

Widdicombe, Sue \& Wooffitt, Robin (1995) The Language of Youth Subcultures. London: Harvester Wheatsheaf. 